\title{
Differences in the genetic basis of leaf dissection between two populations of Crepis tectorum (Asteraceae)
}

\author{
STEFAN ANDERSSON \\ Department of Systematic Botany, University of Lund, O. Vallgatan 18-20, S - 22361 Lund, Sweden
}

\begin{abstract}
In the present investigation, I compare the genetic basis of the dissected leaves characterizing two populations of the annual plant Crepis tectorum in the Baltic region, one on the island of Öland (SE Sweden) and the other in the district of Åland (S Finland). Patterns of segregation in crosses using the same simple-leaved plant as a seed parent demonstrate that finely dissected leaves are completely dominant over weakly lobed leaves, that a single major gene may be responsible for the deeply lobed leaves of the Öland population and that three, perhaps four, major genes control leaf dissection in the Åland population. Different dominant genes may be responsible for leaf dissection in the Aland and Öland populations, as shown by the presence of an entire-leaved plant in the $F_{2}$ progeny of a cross between these populations. These results lend further support to the hypothesis that few genetic changes were involved in the shift from weakly to deeply lobed leaves. Field data from the Öland population indicate low penetrance of the single major gene segregating in crosses with simple-leaved populations.
\end{abstract}

Keywords: adaptation, Crepis tectorum, genetic architecture, leaf shape, penetrance.

\section{Introduction}

The genetic architecture of ecologically important traits is likely to influence the rate at which new adaptations evolve in natural populations. For instance, large differences between species or conspecific populations can have a relatively simple genetic basis (Prazmo, 1965; Macnair, 1977; Gottlieb, 1984; Doebley \& Stec, 1991; Macnair et al., 1992; Orr \& Coyne, 1992; Dorweiler et al., 1993), implying that evolutionary change sometimes occurs more rapidly than would have been the case if numerous loci were involved (Fisher, 1958; Lande, 1981, 1983). The rate of fixation should be greatest for dominant mutations because of the low frequency of individuals homozygous for rare alleles in large outcrossing populations (Haldane, 1924), although there is a potential for fixation of advantageous recessive alleles in (partially) self-fertilizing taxa (Charlesworth, 1992).

The potential for adaptive change is greatly enhanced if a species can achieve the same adaptation by different genetic mechanisms. Indeed, there are ample indications that an adaptation can have a different genetic basis from one population (or species) to another (Macnair, 1976; Cohan, 1984). Hence, ancestral populations probably differed in their response to past selection, depending on the number of genes involved and the dominance relationships among the alleles.

Patterns of segregation in crosses between species or conspecific populations provide useful insights into the genetics of character evolution (Wright, 1968; Grant, 1975; Lande, 1981), particularly when combined with techniques that utilize molecular genetic markers (Doebley \& Stec, 1991; Patterson et al., 1991; deVicente \& Tanksley, 1993; Dorweiler et al., 1993; Van Houten et al., 1994). However, the detection of major gene(s) by traditional or molecular approaches may not indicate a rapid response to selection if the gene has a low penetrance in the natural habitat. Hence, in addition to genetic analyses, it is desirable to determine whether particular gene $(\mathbf{s})$ can be expressed and influence fitness under variable and stressful field conditions (Jackson et al., 1992).

The degree of leaf dissection shows extensive variation among populations of Crepis tectorum (Andersson, 1991a), and increases with general plant vigour (Andersson, 1989a). The finely dissected outline of leaves of (large) plants growing on rocky outcrops on the Baltic island of Öland and in South Finland (Fig. 1) probably evolved as a mechanism to minimize transpiration and overheating by reducing the 'effective leaf size' (Andersson, 1989a, 1991a), as in many other plants adapted to dry, exposed and 
nutrient-poor habitats (Givnish, 1987). In a cross between a population on Öland and an arable weed population on the adjacent mainland (Andersson, 1991a), leaf shape behaved as a simple Mendelian trait with dominance for finely divided leaves, suggesting a potential for rapid evolutionary change in leaf shape. However, more genetic data are needed to examine whether this hypothesis also holds for other dissectedleaved populations of $C$. tectorum.

In the study presented here, the genetic analyses of leaf dissection are extended to establish whether the sharp discontinuities in the Baltic region reflect the geographical distribution of alternative alleles at a single major locus or whether large differences in leaf shape have a more complex genetic basis in populations outside Öland. Apart from carrying out additional crosses, slight differences in leaf shape between dissected-leaved populations on Öland and in South Finland are demonstrated, and field data from the Öland population (Andersson, 1992) are used to examine whether the phenotypic effect of the major gene causing leaf dissection in the greenhouse is obscured in the natural habitat.

\section{Materials and methods}

Crepis tectorum L. (Asteraceae) is a diploid $(2 n=8)$ annual (or biennial) plant, which is geographically differentiated into a widespread weedy taxon and four, partly overlapping outcrop forms in Eurasia, three of which are restricted to the Baltic lowland area (Andersson, 1993a). Unlike plants of the relatively uniform, weedy type, which retain the morphology of more ancestral species in the genus (Babcock, 1947), outcrop plants possess various combinations of characters that are regarded as derived within the species (Andersson, 1993a), including finely divided leaves with leaflets separated to the midrib (Andersson, 1989a, 1991a). The hermaphroditic flowers are arranged in capitula and develop into one-seeded, indehiscent fruits (achenes), which will be referred to as 'seeds' in this paper.

As a first step, plants grown from seed collected at outcrop sites on Öland (seven populations) and on islands in the archipelago of South Finland (three populations; Fig. 1) were compared to confirm preliminary observations of differences in leaf shape between these outcrop forms (Andersson, 1991a). One pressed leaf from each of 10 to 19 plants per population, raised in a greenhouse, was digitized with a video camera connected to a Macintosh computer and automatically scored for each of the characters listed in Table 1. The image acquisition and measurement procedures used the programs IMAGE GRABBER ${ }^{\mathrm{TM}}$ and OPTLLAB ${ }^{\mathrm{TM}}$. Follow- ing transformation of some of the variables to reduce nonnormality and heteroscedasticity (Table 1), the data were subjected to nested ANOVA with region (Öland vs. South Finland) and population (nested within region) as group variables.

Three morphologically distinct outcrop populations were used in the crossing experiment (Fig. 1). Plants derived from a small granite outcrop in a deciduous forest, c. $2 \mathrm{~km} \mathrm{E}$ of the city of Norrköping (SE Sweden), were characterized by narrow and toothed leaves similar to those of more ancestral species of Crepis (Babcock, 1947). Plants with highly dissected leaves were derived from two island sites separated by $450 \mathrm{~km}$. The first site, c. $1.5 \mathrm{~km} \mathrm{~S}$ of Vickleby on Öland, was a more or less treeless area with patches of shallow soil around bare rock (limestone), while the second site, near the village of Storby on the island of Eckerö, Åland (S Finland), was an area with granite outcrops surrounded by sparse pine forest.

Plants from the Norrköping and Aland sites were self-fertile and highly autogamous, while those from Öland showed high levels of self-sterility, as found in previous investigations (Andersson, 1989b). Three generations of self-pollination were used to establish one (partly) inbred line for each of the Norrköping and Aland populations, while the Öland population was represented by a full-sib family derived from a single, male-sterile plant found in another study (Andersson, 1991b) and maintained for three generations by crossing male sterile plants with pollen from male-fertile plants in the same family. When the present study was performed, the Öland family still showed segregation for male fertility.

Examination of leaf outlines shows that the plants used for crossing (Fig. 1) were representative of the populations from which they were derived (Andersson, 1991a) and the average leaf dissection of the partly male-sterile Öland family was close to the average for the source population $\left(t_{39}=1.16, \quad P>0.05\right.$; Andersson, 1991b). However, there is no certainty that the three families were homozygous for all loci controlling leaf shape.

In the summer of 1992, five to ten plants per family (population) were raised, and one or two plants selected from each family as pollen and seed parents; all possible pairwise crosses were performed by rubbing five to seven flowering heads on a seed parent against one or two heads of the pollen donor. Each cross was performed four to five times. Plants from Öland and Åland had distinct anthocyanin spots on the leaves (a dominant character) and served as pollen donors in crosses with a Norrköping plant lacking leaf spots (recessive). This crossing design allowed rapid identification of (anthocyanic) hybrids, and reduced genetic background effects by the use of a single pollen 


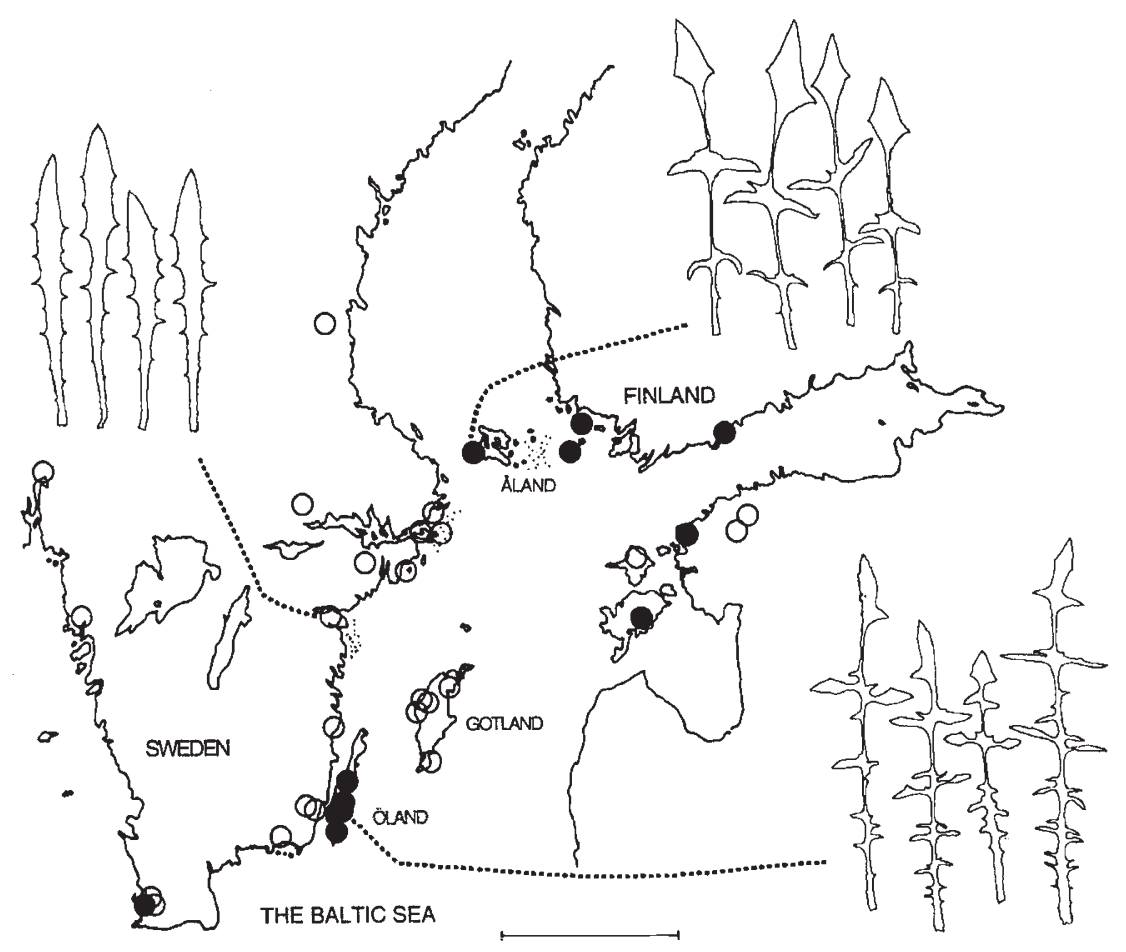

Table 1 Nested analysis of variance (ANOvA) of leaf characters of Crepis tectorum

\begin{tabular}{|c|c|c|c|c|}
\hline \multirow[b]{3}{*}{ Character } & \multicolumn{2}{|c|}{ ANOVA } & \multirow{2}{*}{\multicolumn{2}{|c|}{ Means }} \\
\hline & \multirow{2}{*}{$\begin{array}{l}\text { Between } \\
\text { regions }\end{array}$} & \multirow{2}{*}{$\begin{array}{c}\text { Among } \\
\text { populations }\end{array}$} & & \\
\hline & & & Öland & S Finland \\
\hline Perimeter $(\mathrm{mm})$ & $23.9^{* *}$ & $2.2^{*}$ & 509.6 & 335.3 \\
\hline Area $\left(\mathrm{mm}^{2}\right)$ & $7.0^{*}$ & $6.8^{* * *}$ & 329.9 & 224.0 \\
\hline Length (mm) & $10.6^{*}$ & $3.0^{* *}$ & 83.0 & 69.9 \\
\hline Width (mm) & $1.5 \mathrm{NS}$ & $5.8^{* * *}$ & 19.7 & 17.0 \\
\hline No. of teeth & $32.7^{* * *}$ & $3.2^{* *}$ & 24.7 & 13.1 \\
\hline Area/perimeter & $0.2 \mathrm{NS}$ & $3.2^{* *}$ & 0.663 & 0.677 \\
\hline Width/length & $0.8 \mathrm{NS}$ & $3.6^{* * *}$ & 0.236 & 0.243 \\
\hline Dissection index & $0.2 \mathrm{NS}$ & $3.6^{* * * *}$ & 0.068 & 0.061 \\
\hline No. of teeth/length & $18.1^{* *}$ & $4.0^{* * *}$ & 0.299 & 0.190 \\
\hline
\end{tabular}

Values are $F$-ratios with the mean square (MS) for regions divided by the populations MS and the populations MS divided by the error MS.

All variables except for the number of teeth and area/perimeter were log transformed prior to ANOVA.

Also shown are the regional means (untransformed data).

recipient. In the cross Öland $\times$ Åland, a male-sterile Öland plant was used as the seed parent, while lack of suitable genetic markers precluded attempts to ensure hybrid production in the opposite direction. Reciprocal differences in offspring leaf shape were assumed to be small (see earlier observations in Andersson, 1991a).
Fig. 1 Map showing the locations of populations of Crepis tectorum characterized by leaves with (closed circles) and without (open circles) lobes separated from the midrib (Andersson, 1991a). Also shown is a sample of leaf outlines for each of the populations used in the crossing experiment. Scale bar is $200 \mathrm{~km}$.
All crosses yielded a large number of seeds, some of which were sown later in the same summer. Plants identified as hybrids were self-fertile after self-pollination by hand, and gave rise to large, segregating $F_{2}$ progenies. In the autumn of 1993, all the $F_{2}$ seeds and the remaining parent and $F_{1}$ seeds were sown, the seedlings planted in pots and the pots randomized on a 
greenhouse bench divided into two blocks. Seed germination was high (c. 95 per cent) and seedling mortality was negligible, suggesting a limited potential for selection to influence patterns of segregation after seedling emergence. When all plants had attained maximum leaf dissection (early spring 1994), one rosette leaf from each plant was pressed and leaf dissection was quantified as the ratio of the smallest width to the maximum leaf width, with small values for deeply lobed leaves and values approaching unity for weakly lobed leaves. The ratios were log-transformed before analysis.

For each cross, the parent and $F_{1}$ hybrid means were compared to determine the degree of dominance, an examination was made to determine whether the $F_{2}$ plants segregated into the parental classes and chisquare procedures were used to test various hypotheses regarding the number of factors segregating in the $F_{2}$ generation. A difference in the ratio of plants with simple or dissected leaves in the $F_{2}$ progenies of the crosses Öland $\times$ Norrköping and Alland $\times$ Norrköping would indicate that leaf dissection is governed by different numbers of genes in the Öland and Aland populations, while the presence of simpleleaved plants in the $F_{2}$ of the cross Öland $\times$ Aland would indicate that in these populations leaf dissection is determined by different dominant genes (because of complementary action of recessive genes at different loci).

Environmental changes in the penetrance of the single major gene causing dissected leaves in a greenhouse (see below) was inferred from naturally occurring phenotypes in the Öland population. This data set represents plants in 11 to 13 field plots $\left(0.5 \mathrm{~m}^{2}\right)$ censused for three years, with each individual scored just prior to bolting and classified into one of five categories depending on the ratio of the smallest to the widest point on the lamina (Andersson, 1992; Table 3). Corresponding data from greenhouse-grown progeny from open-pollinated seed families, with measurements taken just prior to bolting (Andersson, 1991b), allowed a comparison of similar sets of genotypes raised in two different environments.

\section{Results}

Whereas nested ANova revealed little effect of region (Öland vs. South Finland) for leaf width, relative leaf area and degree of leaf dissection, the Öland plants produced significantly larger leaves with a longer and more densely toothed margin (Table 1; Fig. 1). All variables showed significant variation among populations within regions.

As preliminary analyses revealed small and nonsignificant differences in leaf dissection of plants raised in different parts of the greenhouse $(P>0.05$, Kruskal-Wallis test for each parent, $F_{1}$ and $F_{2}$ family), the effect of block was ignored in the genetic analyses. Regarding the nonsegregating generations, plants from the Alland and Öland populations had more deeply lobed leaves than those from the Norrköping population (Fig. 2). $F_{1}$ hybrids always resembled the parent with the more dissected leaves, and there was a tendency for the hybrids of the cross Öland $x$ Norrköping to be more variable than other $F_{1}$ families, a possible reflection of the slightly greater variation among plants in the Öland family.

In the $F_{2}$ of the cross Öland $\times$ Norrköping, most of the plants segregated into the parental classes (Fig. 2) in proportions that did not significantly differ from a 3:1 ratio, suggesting single-gene control with complete dominance for deeply lobed leaves (Table 2). By contrast, there was no clear evidence for bimodality in the $F_{2}$ of the cross Alland $\times$ Norrköping (Fig. 2) and only three out of 213 plants fell within the range of the family derived from the simple-leaved population, a result consistent with a three- or four-locus system with the alleles for deeply lobed leaves showing dominance (Table 2). The segregation ratios differed significantly between the two $F_{2}$ progenies (contingency $\chi_{1}^{2}=43.3$, $P<0.001)$.

In the $F_{2}$ of the cross Öland $\times$ Åland, 129 out of 130 plants had finely divided leaves, the remaining plant having narrow leaves without lobes. If the exceptional plant was homozygous recessive at all major loci influencing leaf shape, the parents must have been reciprocally homozygous for alternative alleles at two, three or four independent loci (Table 2). The putative homozygote was vegetatively vigorous but failed to produce viable pollen or seeds (pers. obs.), precluding a more direct test of this interpretation.

Greenhouse data for plants derived from seed collected at the Öland site demonstrate that individuals were homozygous (or heterozygous) for the single major gene segregating in crosses with the simpleleaved population (see above): 881 out of 893 plants had leaves in which the smallest width was less than 20 per cent of the maximum leaf width (Table 3 ), an interval that includes all the Öland and Åland plants used in the crossing experiment (values below -1.6 in Fig. 2). At the field site, only one to six per cent of the plants fell into this category, the majority having entire or weakly lobed leaves. The mean number of leaves per plant was higher in the greenhouse (31.7) than in the field $(2.0$ to 4.0$)$.

\section{Discussion}

Previous work on the variable $C$. tectorum has revealed polygenic inheritance of population differences in leaf 


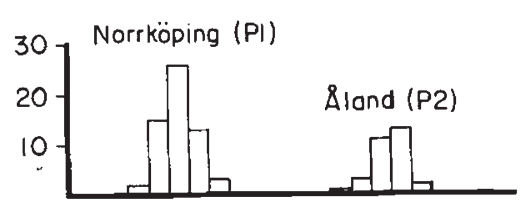

FI

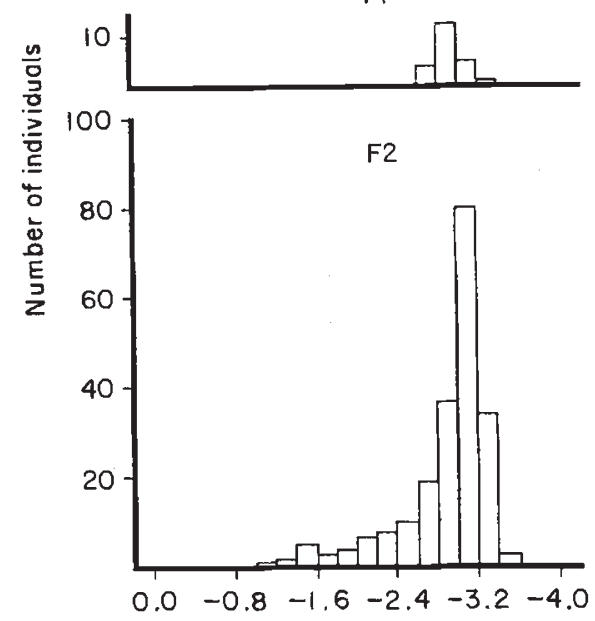

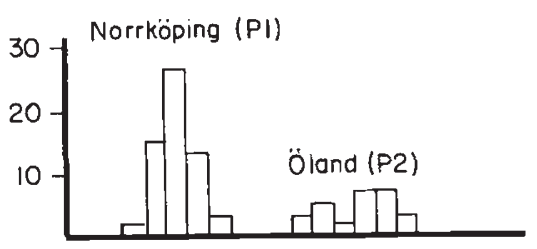
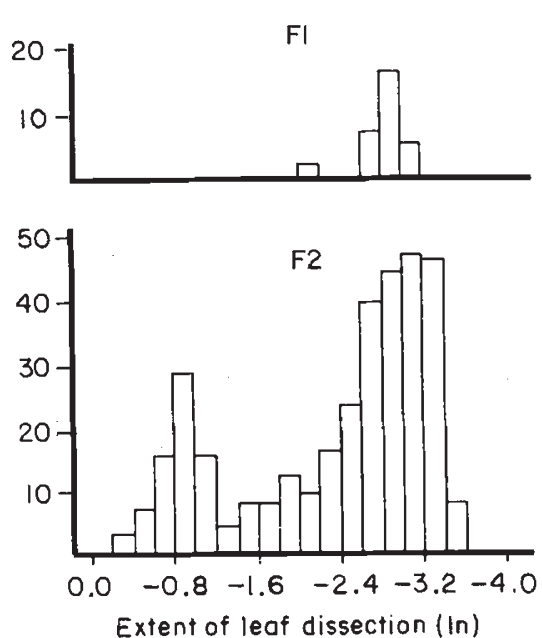
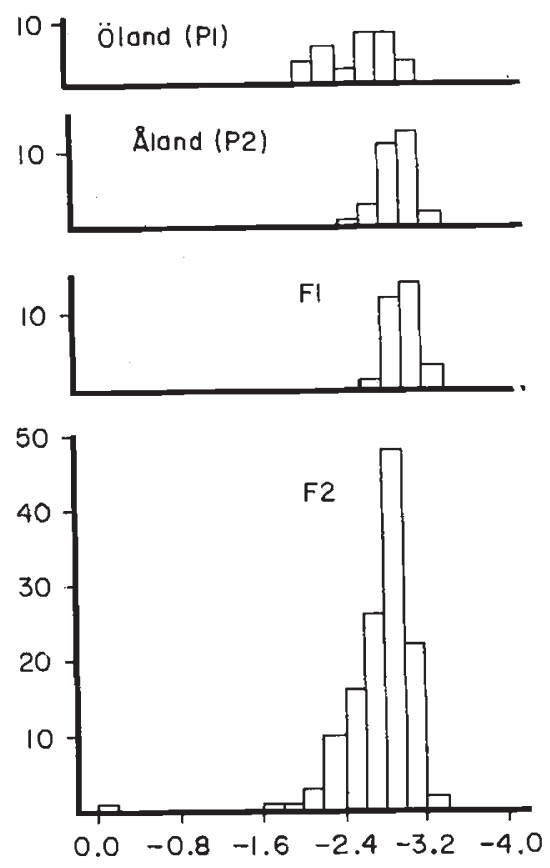

Fig. 2 Histograms showing patterns of segregation of leaf dissection in crosses between populations of Crepis tectorum. Note the reverse scale of the $x$-axis, with increasing leaf dissection towards the right.

Table 2 Patterns of segregation in $\mathrm{F}_{2}$ progenies of three crosses within Crepis tectorum

\begin{tabular}{|c|c|c|c|c|c|}
\hline Cross & $\begin{array}{l}\text { Deeply } \\
\text { lobed }\end{array}$ & $\begin{array}{l}\text { Weakly } \\
\text { lobed }\end{array}$ & Model & Exp. & $\chi^{2}$ \\
\hline \multirow[t]{2}{*}{ Öland $\times$ Norrköping } & \multirow[t]{2}{*}{260} & \multirow[t]{2}{*}{72} & One locus & $3: 1$ & 1.94 NS \\
\hline & & & Two loci & $15: 1$ & $135.02^{* * * *}$ \\
\hline \multirow[t]{5}{*}{ Åland $\times$ Norrköping } & \multirow[t]{5}{*}{210} & \multirow[t]{5}{*}{3} & One locus & $3: 1$ & $63.23^{* * *}$ \\
\hline & & & Two loci & $15: 1$ & $8.52^{* *}$ \\
\hline & & & Three loci & $63: 1$ & $0.01 \mathrm{NS}$ \\
\hline & & & Four loci & $255: 1$ & $3.36 \mathrm{NS}$ \\
\hline & & & Five loci & $1023: 1$ & $25.28^{* * * *}$ \\
\hline \multirow[t]{4}{*}{ Åland $\times$ Öland } & \multirow[t]{4}{*}{129} & \multirow[t]{4}{*}{1} & One locus & $15: 1$ & $6.67 * *$ \\
\hline & & & Two loci & $63: 1$ & $0.14 \mathrm{NS}$ \\
\hline & & & Three loci & $255: 1$ & $0.00 \mathrm{NS}$ \\
\hline & & & Four loci & 1023:1 & $1.10 \mathrm{NS}$ \\
\hline
\end{tabular}

Parental ranges in Fig. 2 were used to classify plants as deeply or weakly lobed (log ratio of the smallest to the widest point on the lamina less than or greater than $-1.4)$.

Observed frequencies were compared with frequencies predicted according to different hypotheses regarding the number of independent loci contributing to differences between populations (Öland $\times$ Norrköping, Åland $\times$ Norrköping) or the number of loci with different alleles for deeply lobed leaves (Åland $\times$ Öland). All models assume complete dominance for dissected leaves. Yate's correction for continuity was applied when expected frequencies were lower than 5 .

size, plant height, branch length, involucre height, flower and seed size (Andersson, 1993a), and a tendency for these characters to be positively correlated at the genetic level (Andersson, 1993b). How- ever, results of the present study (Fig. 1, Table 2) confirm previous observations (Andersson, 1991a) that one major gene may be responsible for the striking difference between the finely divided leaves of outcrop 
Table 3 The frequency of Crepis tectorum with different degrees of leaf dissection in the Öland population, which appears to be homozygous for a dominant gene causing deeply lobed leaves in the greenhouse. The average number of rosette leaves per plant is also presented

\begin{tabular}{lrrrrrr}
\hline & \multicolumn{4}{c}{ Ratio of smallest to widest point on lamina } & \\
\cline { 2 - 5 } Year & $>0.80$ & $0.80-0.60$ & $0.60-0.40$ & $0.40-0.20$ & $<0.20$ & No. leaves \\
\hline Greenhouse 1988 & 0 & 0 & 0 & 12 & 881 & 31.7 \\
Field 1986 & 492 & 238 & 258 & 228 & 60 & 4.0 \\
Field 1987 & 766 & 17 & 14 & 9 & 5 & 2.1 \\
Field 1988 & 1272 & 41 & 16 & 5 & 3 & 2.0 \\
\hline
\end{tabular}

Data from Andersson (1991b, 1992).

plants on the island of Öland and the simple leaves of populations on the adjacent mainland. This finding agrees with the discrete inheritance of leaf shape in crosses within $C$. capillaris (Collins, 1924) and between species of Lactuca (Whitaker, 1944), and with other studies demonstrating a simple genetic control of differences in shape, architecture or orientation (Prazmo, 1965; Gottlieb, 1984; Dorweiler et al., 1993). Of course, evidence for monogenic inheritance does not exclude the influence of genes with smaller phenotypic effects or genetic factors that modify the expression of the major gene( $\mathrm{s}$ ), as demonstrated by the presence of quantitative genetic variation for leaf shape in the Öland population (Andersson, 1991b).

Genetic data from the present investigation show that drastic changes in leaf dissection can be achieved by different genetic pathways; three or four genes were responsible for the deeply lobed leaves of plants derived from an outcrop site in South Finland (Åland). Whether any of these genes is allelic to the single major gene conferring leaf dissection in the Öland population is still uncertain, but it seems safe to conclude that different genetic mechanisms are responsible for the finely divided leaves of these populations. Other cases in which the genetic basis of the same adaptation differs between species or conspecific populations of plants include floral morphology (Prazmo, 1965; Mayer \& Charlesworth, 1992; Fenster \& Barrett, 1994), heavy metal tolerance (Macnair, 1976; Schat et al., 1993) and herbicide resistance (Miller et al., 1973).

Plants of C. tectorum growing on outcrops on Öland differ from those in South Finland in having shorter and more densely branched stems, higher levels of selfsterility and smaller seeds, a manifestation of different selection and/or migration histories since the presumed origin from populations on the surrounding mainland (Andersson, 1993a). When combined with the slight differences in lobe shape between plants from Öland and South Finland (Table 1) and the widely different segregations in crosses using the same simpleleaved plant as a seed parent (Fig. 2), my results lead to the suggestion that dissected-leaved populations have evolved repeatedly in the Baltic region. More detailed genetic data are needed to examine whether the multiple-origin hypothesis also applies to local populations on Öland and in the southern parts of Finland, and to the scattered occurrence of dissected-leaved populations in areas lacking outcrops (Andersson, 1989a, 1991a).

Theory predicts differences between populations in their response to similar selection pressures, depending on the number of loci contributing to phenotypic variation (Lande, 1983) and the pattern of dominance among the alleles at these loci (Haldane, 1924). Regarding leaf shape in $C$. tectorum, the $F_{1}$ hybrids resembled the dissected-leaved parent in each of three crosses (this study; Andersson, 1991a), suggesting little variation in the direction and magnitude of dominance. Further, each of the dominant factors conferring deeply lobed leaves in the Alland population appears to have a similar phenotypic effect as the single gene contributing to leaf dissection in the Öland population. If this interpretation is correct, a single allelic substitution could be involved in the transition from weakly to deeply lobed leaves in both cases. However, the final approach to fixation of a dominant allele is likely to be a relatively slow process (Johnson, 1976), particularly when the recessive (ancestral) allele is masked by dominant alleles at more than one locus. Hence, it may be necessary to invoke genetic drift, inbreeding or other mechanisms (in addition to selection) to explain the (apparent) fixation of dominant alleles at multiple loci in the Åland population.

For environmentally plastic characters like leaf shape, one would expect microsite heterogeneity to obscure heritable differences among individuals, thus retarding the establishment and spread of advantageous mutations. Indeed, in a natural population of $C$. 
tectorum with little (apparent) segregation at a major locus influencing leaf shape, a surprisingly small fraction of the plants was capable of expressing the finely divided leaves typical of plants raised in a greenhouse. In this context, it is worth noting that the average leaf dissection of field-collected plants from Öland (and South Finland) still exceeds the average leaf dissection of plants from other regions and habitats (Andersson, 1990).

Rosette leaf number, an indicator of the growth conditions experienced by each plant, is a primary determinant of leaf dissection, as evidenced by the large size attained by plants in the greenhouse and the positive association between plant vigour and degree of leaf dissection (Andersson, 1992). In fact, the dissipation of excess heat associated with dividing the leaf area into smaller leaflets (Givnish, 1987) is probably most important for the most vigorous plants which also tend to have the largest leaves (Andersson, 1992). Given the low penetrance, the evolutionary shift from weakly to deeply lobed leaves may have been a relatively slow process, despite evidence for simple patterns of inheritance under uniform greenhouse conditions (this study) and strong selection at the phenotypic level (Andersson, 1992). Interestingly, there are some indications that the Åland plants attain maximum leaf dissection earlier in their ontogeny than plants in the Öland population (unpublished observations), raising the possibility that the penetrance increases with the number of genes for leaf dissection, but more field data are needed to test this hypothesis.

\section{Acknowledgements}

H. C. Prentice provided valuable comments on the manuscript. Technical assistance by Rune Svensson is also acknowledged.

\section{References}

ANDERSSON, s. 1989a. Variation in heteroblastic succession among populations of Crepis tectorum. Nord. J. Bot., 8, 565-573.

ANDERSSON, s. $1989 \mathrm{~b}$. The evolution of self-fertility in Crepis tectorum (Asteraceae). Pl. Syst. Evol., 168, 227-236.

ANDERsson, s, 1990. A phenetic study of Crepis tectorum in Fennoscandia and Estonia. Nord. J. Bot., 9, 589-600.

ANDERSSON, S. 1991a. Geographical variation and genetic analysis of leaf shape in Crepis tectorum (Asteraceae). Pl. Syst. Evol., 178, 247-258.

ANDERSSON, s. 1991b. Quantitative genetic variation in a population of Crepis tectorum ssp. pumila (Asteraceae). Biol. J. Linn. Soc., 44, 381-393.

ANDERsSON, s. 1992. Phenotypic selection in a population of Crepis tectorum ssp. pumila (Asteraceae). Can.J. Bot., 70, 89-95.
ANDERSSON, s. 1993a. Morphometric differentiation, patterns of interfertility, and the genetic basis of character evolution in Crepis tectorum (Asteraceae). Pl. Syst. Evol., 184, 27-40.

ANDERsson, s. 1993b. Population differentiation in Crepis tectorum (Asteraceae): patterns of correlation among characters. Biol. J. Linn. Soc., 49, 185-194.

BABCOCK, Е. в. 1947. The genus Crepis I-II. University of California Press, Los Angeles.

CHARLESWORTH, B. 1992. Evolutionary rates in partially selffertilizing species. Am. Nat., 140, 126-148.

COHAN, F. M. 1984. Can uniform selection retard random genetic divergence between isolated conspecific populations? Evolution, 38, 495-504.

Collins, J. L. 1924. Inheritance in Crepis capillaris. III. Nineteen morphological and three physiological characters. Univ. Calif. Publ. Agric. Sci., 2, 249-296.

DEVICENTE, M. C. AND TANKSLEY, S. D. 1993. QTL analysis of transgressive segregation in an interspecific tomato cross. Heredity, 134, 585-596.

DOEBLEY, J. AND STEC, A. 1991. Genetic analysis of the morphological differences between maize and teosinte. Genetics, 129, 285-295.

DORWEILER, J., STEC, A., KERMICLE, J. AND DOEBLEY, J. 1993. Teosinte glume architecture 1: a genetic locus controlling a key step in maize evolution. Science, 262, 233-235.

FENSTER, C. B. AND BARRETT, S. C. H. 1994. Inheritance of matingsystem modifier genes in Eichhornia paniculata (Pontederiaceae). Heredity, 72, 433-445.

FISHER, R. A. 1958. The Genetical Theory of Natural Selection, 2nd edn. Dover, New York.

GIVNISH, T. J. 1987. Comparative studies of leaf form: assessing the relative roles of selective pressures and phylogenetic constraints. New Phytol. (Suppl.), 106, 131-160.

GOTTLIEB, L. D. 1984. Genetics and morphological evolution in plants. Am. Nat., 123, 681-709.

GRANT, v. 1975. Genetics of Flowering Plants. Columbia University Press, New York and London.

HALDANE, J. B. S. 1924. A mathematical theory of natural and artificial selection. Trans. Camb. Phil. Soc., 23, 19-41.

JACKSON, L. L., DEWALD, C. L. AND BOHLEN, C. C. 1992. A macromutation in Tripsacum dactyloides (Poaceae): consequences for seed size, germination, and seedling establishment. Am. J. Bot., 79, 1031-1038.

JOHNSON, C. 1976. Introduction to Natural Selection. University Park Press, Baltimore.

LANDE, R. 1981. The minimum number of genes contributing to quantitative variation between and within populations. Genetics, 99, 541-553.

LANDE, R. 1983. The response to selection on major and minor mutations affecting a metrical trait. Heredity, 50, $47-65$

MACNAIR, M. R. 1976. The Genetics of Copper Tolerance in Mimulus guttatus (Scrophulariaceae). PhD Thesis, University of Liverpool.

MACNAIR, M. R. 1977. Major genes for copper tolerance in Mimulus guttatus. Nature, 268, 428-430.

MACNAIR, M. R., CUMBES, Q. J. AND MEHARG, A. A. 1992. The genetics of arsenate tolerance in Yorkshire fog, Holcus lanatus L. Heredity, 69, 325-335. 
MAYER, S. S. AND CHARLESWORTH, D. 1992. Genetic evidence for multiple origins of dioecy in the Hawaiian shrub Wikstroemia (Thymeleaceae). Evolution, 46, 207-215.

MILLER, J. C., BAKER, L. R. AND PENNER, D. 1973. Inheritance of tolerance to chloramber-methyl-ester in cucumber. J. Am. Soc. Hort. Sci., 98, 386-389.

ORR, H. A. AND COYNE, J. A. 1992. The genetics of adaptation: a reassessment. Am. Nat., 140, 725-742.

PATTERSON, A. H., DAMON, S. H., HEWITT, J., ZAMIR, D., RABINOWITCH, H., LINCOLN, S., LANDER, E. AND TANKSLEY, S. 1991. Mendelian factors underlying quantitative traits in tomato: comparison across species, generations and environments. Genetics, 127, 181-197.

PRAZMo, w. 1965. Cytogenetic studies on the genus Aquilegia, III. Inheritance of the traits distinguishing different complexes in the genus Aquilegia. Acta Soc. Bot. Pol., 34, 403-437.
SCHAT, H., KUIPER, E., TEN BOOKUM, W. M. AND VOOIJS, R. 1993. A general model for the genetic control of copper tolerance in Silene vulgaris: evidence from crosses between plants from different tolerant populations. Heredity, $\mathbf{7 0}$, 142-147.

VAN HOUTEN, W., VAN RAAMSDONK, L. AND BACHMANN, K. 1994. Intraspecific evolution of Microseris pygmaea (Asteraceae, Lactuceae) analyzed by cosegregation of phenotypic characters (QTLs) and molecular markers (RAPDs). $P l$. Syst. Evol., 190, 49-67.

WHITAKER, T. W. 1944. The inheritance of certain characters in a cross of two American species of Lactuca. Bull. Torrey Bot. Club, 71, 347-355.

WRIGHT, s. 1968. Evolution and the Genetics of Populations, vol. 1, Genetic and Biometric Foundations. University of Chicago Press, Chicago. 